\title{
Testing a pyriproxyfen auto-dissemination station attractive to gravid Anopheles gambiae sensu stricto for the development of a novel attract-release -and-kill strategy for malaria vector control
}

\author{
Oscar Mbare ${ }^{1,2^{*}}$, Steven W. Lindsay ${ }^{3}$ and Ulrike Fillinger ${ }^{1}$
}

\begin{abstract}
Background: Larviciding is an effective supplementary tool for malaria vector control, but the identification and accessibility of aquatic habitats impedes application. Dissemination of the insect growth regulator, pyriproxyfen (PPF), by gravid Anopheles might constitute a novel application strategy. This study aimed to explore the feasibility of using an attractive bait-station to contaminate gravid Anopheles gambiae sensu stricto with PPF and subsequently transfer PPF to larval habitats.

Methods: A bait-station was developed comprising of an artificial pond containing water treated with $20 \mathrm{ppm}$ cedrol, an oviposition attractant, and a netting-cover treated with PPF. Three identical semi-field cages were used to assess the potential of gravid Anopheles to transfer PPF from the bait-station to ponds. Gravid females were released in two semi-field cages, one with PPF on its bait-station (test) and one without PPF (control). No mosquitoes were released in the third cage with a PPF-treated station (control). Transfer of PPF to open ponds was assessed by monitoring emergence of late instar insectary-reared larvae introduced into the ponds. The amount of PPF carried by a mosquito and transferred to water was quantified using liquid chromatography-mass spectrometry.

Results: In the controls, 86\% (95\% Cl 81-89\%) of larvae introduced into open ponds developed into adults, indicating that wind did not distribute PPF in absence of mosquitoes. Emergence inhibition was observed in the test cage but was dependent on the distance between pond and bait-station. Only 25\% (95\% Cl 22-29\%) of larvae emerged as adults from ponds $4 \mathrm{~m}$ from the bait-station, but $92 \%$ (95\% Cl 89-94\%) emerged from ponds $10 \mathrm{~m}$ away. Each mosquito was contaminated on average with $112 \mu \mathrm{g}(95 \% \mathrm{Cl} 93-123 \mu \mathrm{g})$ PPF resulting in the transfer of $230 \mathrm{ng} / \mathrm{L}(95 \% \mathrm{Cl} 180-290 \mathrm{ng} / \mathrm{L})$ PPF to $100 \mathrm{ml}$ volumes of water.

Conclusions: The bait-stations successfully attracted gravid females which were subsequently dusted with effective levels of PPF. However, in this study design, attraction and dissemination was limited to short distances. To make this approach feasible for malaria vector control, stronger attractants that lure gravid females from longer distances, in landscapes with many water bodies, and better PPF delivery systems are needed.
\end{abstract}

Keywords: Anopheles gambiae sensu stricto, Pyriproxyfen, Oviposition, Vector control

* Correspondence: ombare@icipe.org

${ }^{1}$ International Centre of Insect Physiology and Ecology, Human Health

Theme, Nairobi, Kenya

${ }^{2}$ London School of Hygiene and Tropical Medicine, London, UK

Full list of author information is available at the end of the article

(c) The Author(s). 2019 Open Access This article is distributed under the terms of the Creative Commons Attribution 4.0 International License (http://creativecommons.org/licenses/by/4.0/), which permits unrestricted use, distribution, and reproduction in any medium, provided you give appropriate credit to the original author(s) and the source, provide a link to the Creative Commons license, and indicate if changes were made. The Creative Commons Public Domain Dedication waiver (http://creativecommons.org/publicdomain/zero/1.0/) applies to the data made available in this article, unless otherwise stated. 


\section{Background}

Improved access to the core malaria control interventions namely vector control, effective diagnosis and prompt treatment have greatly contributed to the global reduction in malaria morbidity and mortality [1-3]. However, recent World Malaria Reports from 2017 and 2018 indicate that this remarkable progress has stalled $[1,4]$. This worrying trend emphasizes the need to explore additional tools for malaria prevention to supplement the current frontline measures and ensure that the gains achieved in the last decade are sustained [5-7].

Malaria control programs are encouraged to adopt integrated vector management strategies to increase efficacy, cost-effectiveness and sustainability of disease control [7, 8]. Larval source management (LSM) targeting immature mosquito vectors in their aquatic habitats, such as larviciding and environmental management, can effectively serve as supplementary vector control measures $[9,10]$. Studies in East Africa highlighted the benefit of combining long-lasting insecticidal nets (LLINs) and larviciding with microbial larvicides for reducing transmission [11-14]. However, the challenge associated specifically with larviciding is the need to reach all available and potentially suitable aquatic habitats in an intervention area [15-18], many of which might only be reached by aerial application. Whilst it has been suggested that larviciding might be targeted only at a proportion of most productive habitats [19, 20], habitat productivity is still poorly understood and not easily predicted by application teams [21-23].

Auto-dissemination, a novel strategy that exploits the adult insect as a 'vehicle' to deliver insecticide, might be one way of addressing this challenge. This strategy has been shown to be effective in the control of Aedes mosquito [24-27], leading to an increased interest in its exploration for control of Afrotropical malaria vectors $[28,29]$. Semi-field studies conducted in Tanzania provide the first evidence of the potential of An. arabiensis to transfer the insecticide pyriproxyfen (PPF) from resting surfaces to larval habitats, consequently inhibiting larval development [30-32]. However, these studies were implemented at extremely high mosquito population densities that are unlikely to occur under natural conditions. Furthermore, the targeting of host-seeking mosquitoes before or shortly after bloodmeals for contact with PPF is likely to cause a large proportion of the females to become sterilized and not develop into gravid females [33-37]. We recently showed that a female that is not gravid is significantly less likely to visit an oviposition habitat, and hence transfer PPF to a water body, and that the optimum time for exposing female Anopheles gambiae sensu stricto to PPF for auto-dissemination is close to oviposition [35]. Consequently, the aim of this study was to design an attractive bait-station to contaminate gravid An. gambiae s.s. with PPF and to test the efficiency of PPF transfer to open ponds under semi-field conditions.

\section{Methods \\ Study site}

Experiments were carried out in large netting-screened semi-field cages $(10.8 \mathrm{~m}$ long $\times 6.7 \mathrm{~m}$ wide $\times 2.4 \mathrm{~m}$ high $)$ at the International Centre of Insect Physiology and Ecology, Thomas Odhiambo Campus (icipe-TOC), located on the shore of Lake Victoria in Mbita, Homa Bay county, western Kenya (geographic coordinates $0^{0} 26^{\prime}$ 06.19" S, $34^{0} 12^{\prime} 53.13^{\prime \prime}$ E; altitude $1137 \mathrm{~m}$ above sea level). The cages had a sand floor and did not contain any vegetation. Mbita is characterized by tropical climate with an annual average minimum temperature of $16^{\circ} \mathrm{C}$ and maximum temperature of $29^{\circ} \mathrm{C}$. The area experiences two rainy seasons; the long rains between March and June and the short rains between October and December.

\section{Test insecticide}

An experimental formulation of dust, with particles $12 \mu \mathrm{m}$ diameter, containing $10 \%$ of pyriproxyfen (PPF) (Sumilarv, Sumitomo Chemical Company) was used in all experiments.

\section{Mosquitoes}

Anopheles gambiae s.s. (Mbita strain) larvae and adults used in this study were obtained from the mosquito insectaries at icipe-TOC. Immature stages were reared in a semi-field cage at ambient conditions with average daily temperature of $25-28{ }^{\circ} \mathrm{C}$, relative humidity of $68-75 \%$ and natural lighting. Mosquito larvae were reared in round plastic tubs (diameter $60 \mathrm{~cm}$ ) filled with $5 \mathrm{~L}$ water (5 cm deep) from Lake Victoria filtered through a charcoal-sand filter. Mosquito larvae were fed with a pinch of fish food (Tetramin@Baby) twice daily. Third (late) instar mosquito larvae were randomly selected from different tubs to ensure that cohorts of larvae used in experiments were a representative sample of the size distribution of the experimental larval population. Adult mosquitoes were held in mosquito-netting covered cages $(30 \mathrm{~cm} \times 30 \mathrm{~cm} \times 30 \mathrm{~cm})$ in a holding room with ambient climate conditions and provided with $6 \%$ glucose solution ad libitum. Three-day old females were allowed to feed on a human arm on two consecutive nights. Gravid mosquitoes were used for experiments in this study.

\section{Development of a bait-station}

\section{Contamination of adult An. gambiae s.s. with PPF}

Water vapour has been shown to attract gravid malaria vectors [38] and hence it was considered essential to include water in the bait-station. Females were prevented from accessing the water to lay eggs using fly gauze (black fibre-glass netting gauze, mesh size $1 \mathrm{~mm} \times 1 \mathrm{~mm}$ ). 
To determine the best method to treat netting surfaces with PPF for efficient contamination of mosquitoes, preliminary cage tests were conducted in small-sized cages $(30 \mathrm{~cm} \times 30 \mathrm{~cm} \times 30 \mathrm{~cm})$. Two methods of applying PPF on the netting gauze that served as the dissemination platforms were compared. First, the netting gauze (diameter 7 $\mathrm{cm}$ ) was treated with $1 \mathrm{~g}$ of PPF dust applied with a soft brush to ensure uniform spreading of the PPF over the netting surface. Second, $1 \mathrm{~g}$ of PPF dust was mixed with 2 $\mathrm{ml}$ of cooking oil and applied to the netting gauze with a soft brush and left to dry in the air for $30 \mathrm{~min}$. The rationale for this was to test a formulation that would be easier to apply and less likely to be distributed by wind.

Each experimental cage was provided with two glass cups (Pyrex ${ }^{\circ}$, capacity $100 \mathrm{ml}$, diameter $7 \mathrm{~cm}$ ) and the cups were placed at the diagonal corners of the cage, approximately $26 \mathrm{~cm}$ apart. The first cup in each cage was filled with 100 $\mathrm{ml}$ non-chlorinated tap water and left open for gravid mosquitoes to lay eggs. The second cup, serving as the bait-station, was filled with six-day old soil infusion previously shown to attract gravid An. gambiae s.s [39]. Soil infusion was prepared by incubating $15 \mathrm{~L}$ of non-chlorinated tap water with $2 \mathrm{~kg}$ of soil collected from a known breeding habitat of An. gambiae sensu lato [39] which was dry at the time of collection. Infusions were prepared in round plastic tubs (diameter $0.42 \mathrm{~m}$ ) and left for six days before use in experiments as described in detail previously [39]. The top of the bait-station in the control cages was covered with untreated netting gauze while in the test cages it was covered with netting gauze treated with either PPF dust or PPF dust formulated in oil. In each cage five gravid $A n$. gambiae s.s. were released at 18:00 h and left overnight.
The following morning, open oviposition cups were assessed for the presence of eggs. To confirm the transfer of PPF in test cages, 10 insectary-reared late instar $A n$. gambiae s.s. larvae were introduced into oviposition cups in all cages and monitored for adult emergence. Introduced larvae were fed daily on a pinch of Tetramin Baby fish food. Pupae that developed were transferred with a small volume of water from the oviposition cup into plastic cups (diameter $7 \mathrm{~cm}$ ) and monitored for adult emergence. It took 6-7 days for all larvae introduced into the oviposition cups to develop into adults or die. These experiments were conducted over three rounds on separate dates. There were five replicate cages per treatment in each experimental round, thus in total there were 15 cages with untreated bait-stations, 15 cages with bait-stations treated with PPF dust and 15 cages with bait-stations treated with PPF dust formulated in oil. Oviposition cups were randomly allocated to one of the four corners in the cages.

\section{Luring gravid An. gambiae s.s. to a pond}

Preliminary experiments were conducted in a semifield cage (Fig. 1) to compare attractiveness of two substrates that attract gravid An. gambiae s.s.: a sixday old soil-infusion [39] and the sesquiterpene alcohol, cedrol (Cedrol $\geq 99.0 \%$ (sum of enantiomers, GC, Sigma-Aldrich, Steinheim, USA) [40]. The two substrates were evaluated separately on different dates. Four artificial ponds were created by digging holes in the sand at the four corners of the cage, and each hole was filled with a round enamel tub (diameter $0.42 \mathrm{~m}$, depth $8 \mathrm{~cm}$ ). The tubs were placed $1 \mathrm{~m}$ away from the nearest wall. During each experimental round, three of

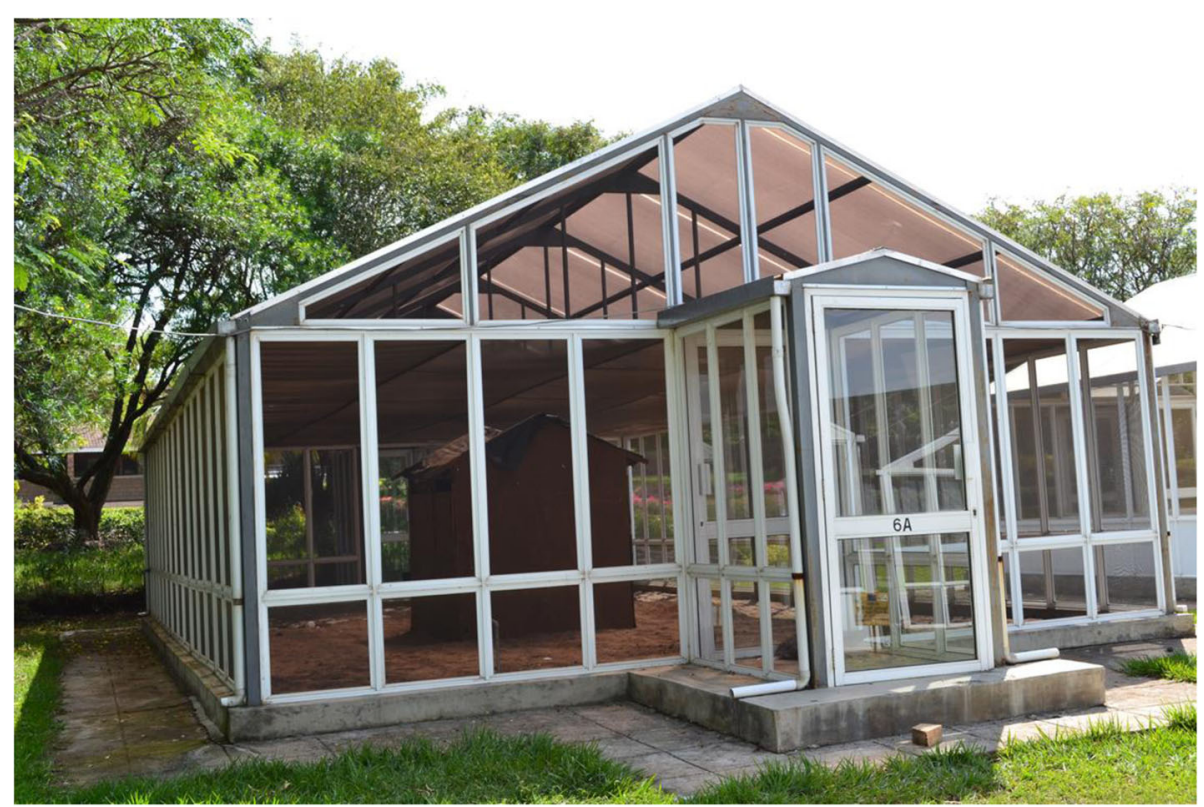

Fig. 1 Semi-field cage showing artificial hut constructed at the centre of the semi-field cage 
the tubs were filled with $7 \mathrm{~L}$ of non-chlorinated tap water as oviposition habitats while the fourth tub was filled with a test substrate to attract gravid females introduced into the cage. The test substrate consisted of either $7 \mathrm{~L}$ of six-day old soil infusion or $7 \mathrm{~L}$ of nonchlorinated tap water treated with cedrol. Two concentrations of cedrol were tested sequentially: $5 \mathrm{ppm}$ and $20 \mathrm{ppm}$. Cedrol was prepared in ethanol by first preparing a stock solution of $10,000 \mathrm{ppm}$ by dissolving $150 \mathrm{mg}$ of cedrol to $15 \mathrm{ml}$ of absolute ethanol $(\geq 99.8 \%$ (GC), Sigma Aldrich). Dilutions were made by adding the appropriate volume of stock solution to water in the pond. For instance, $5 \mathrm{ppm}$ cedrol was prepared by adding $3.5 \mathrm{ml}$ of stock solution into $7 \mathrm{~L}$ of water. Similarly, $20 \mathrm{ppm}$ cedrol was prepared by adding $14 \mathrm{ml}$ of stock solution to the $7 \mathrm{~L}$ of water in the artificial pond.

A small wooden hut $(1.78 \mathrm{~m}$ long $\times 1.73$ wide $\times 1.80 \mathrm{~m}$ high) was set up in the centre of the semi-field cage (Fig. 1) to simulate the natural indoor environment where female An. gambiae s.s. take a blood-meal and rest till they are gravid [41]. The hut had a door and two windows that were shut when the experiment was in progress. Two open eaves $(1.70 \mathrm{~m} \times 0.18 \mathrm{~m})$ located at opposite sides of the hut served as the only exit points for the mosquitoes released in the hut. In each experimental night 200 gravid $A n$. gambiae s.s. were released at 18:00 h inside the hut.

To measure the number of mosquitoes visiting the ponds, the top of each pond was covered by a black fibreglass netting gauze cut to size (diameter $0.42 \mathrm{~m}$ ) on which a fine film of insect glue was sprayed (Oeco insect spray, Oecos, UK) to trap the gravid females as they searched for oviposition substrates. At 6:00 h the following morning the number of females trapped on the sticky screens was counted. Each of the test substrates was evaluated over 12 replicate nights with fresh oviposition substrates and fresh batches of mosquitoes used each night. The four ponds (three ponds filled with non-chlorinated water and the pond containing the test substrate) were randomly allocated in all four corners of the semi-field cage using a randomized complete block design.

Evaluation of the auto-dissemination of PPF by gravid $A n$. gambiae s.s. from the bait-station to larval habitats

These experiments were conducted in three identical semi-field cages which contained a wooden hut at the centre and four enamel tubs used to create artificial ponds at the corners of each cage as described above (Fig. 2). The experiments were done under standardized conditions without vegetation. In the first semi-field cage, three ponds were filled with $7 \mathrm{~L}$ of non-chlorinated tap water each and left open for mosquito oviposition, while the fourth pond serving as the bait-station contained $7 \mathrm{~L}$ of water treated with $20 \mathrm{ppm}$ cedrol as described above. A netting gauze (diameter $0.42 \mathrm{~m}$ ) treated with $3.5 \mathrm{~g}$ PPF dust (average $20.3 \mathrm{~g} \mathrm{PPF} / \mathrm{m}^{2}$ retained on gauze on weighing) was placed on top of the cedroltreated pond. The three open ponds were $4.4 \mathrm{~m}, 8.4 \mathrm{~m}$ and $10.3 \mathrm{~m}$ away from the bait-station (Fig. 2). The set-up in the second semi-field cage was the same as the first, except that no mosquitoes were released in the cage. The aim here was to investigate if PPF might be distributed by air movement to neighbouring ponds, rather than mosquitoes. In the third semi-field cage, mosquitoes were released but the netting gauze placed on top of the bait-station was left untreated. This set-up served to investigate natural adult mosquito emergence rates from ponds when no

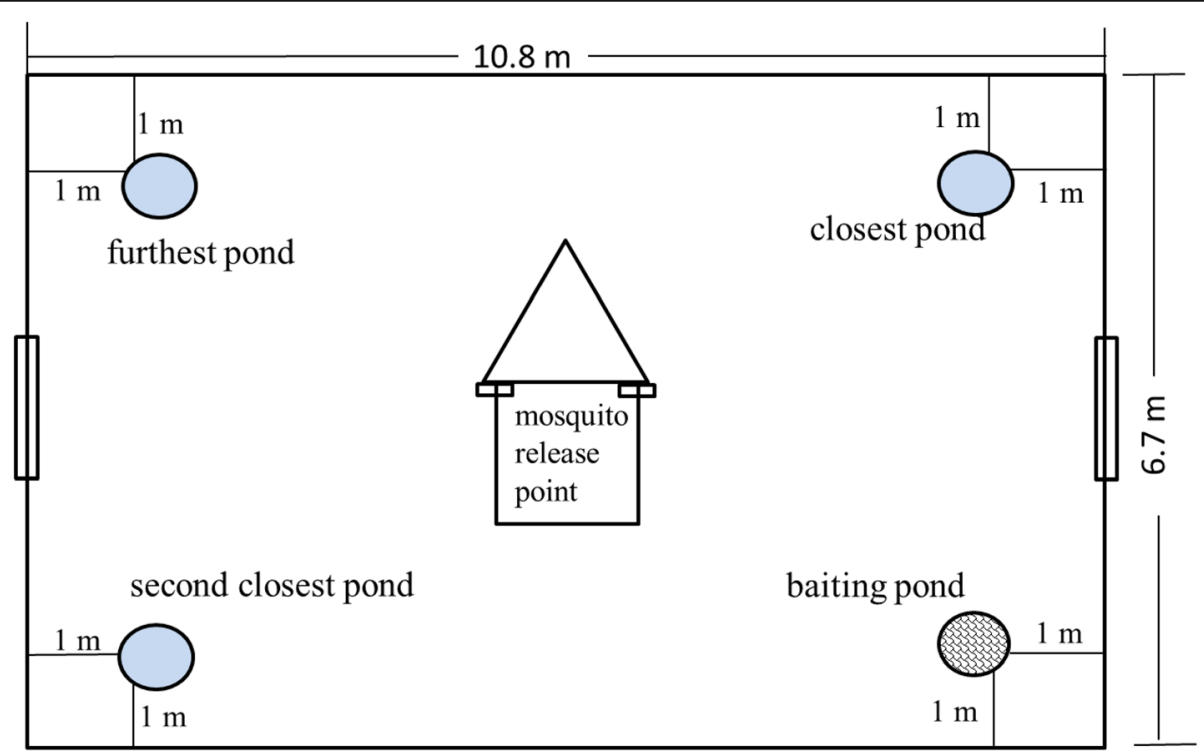

Fig. 2 Schematic representation of semi-field cage showing location of ponds and the artificial hut that serve as release point of gravid mosquitoes 
insecticide was present in the semi-field cage. Two hundred gravid An. gambiae s.s. were released at $18.00 \mathrm{~h}$ per experimental night inside the hut and allowed to disperse through the open eaves.

The following morning, all open ponds in the three semi-field cages were visually assessed for the presence of eggs laid. Eggs were not counted since an exact estimate would have required removing the eggs from the ponds using a sieve or similar tools potentially interfering with the amount of PPF transferred. To ensure sufficient replication of the experiment, the impact of PPF was not assessed by monitoring the development of eggs laid in ponds by exposed mosquitoes. That would have taken approximately two weeks to complete per replicate and, therefore, over half a year to complete 12 replicates [42]. Instead, the possible transfer of PPF by females to the ponds was assessed by monitoring the adult emergence of 50 insectary-reared late instar An. gambiae s.s. larvae that were introduced into each open pond in all three experimental set-ups. The larvae were introduced into the ponds in the morning after the gravid females were released. Introduced larvae were fed daily with a pinch of Tetramin ${ }^{\circ}$ Baby Fish food. Any pupae that developed in the three ponds were transferred with a small volume of water from the pond into $200 \mathrm{ml}$ plastic cups (diameter $7 \mathrm{~cm}$ ) and monitored for adult emergence. It took 6-7 days for all introduced larvae to develop into adults or die. Thereafter the ponds and hut were cleaned and all remaining flying adult mosquitoes in cages aspirated using a motorized backpack aspirator (John W. Hock Company, USA). A new round of replicates was set-up with fresh oviposition substrates and fresh batches of gravid mosquitoes and mosquito larvae. The experiment was replicated over 12 rounds with each round lasting seven days. The four ponds were randomly allocated in all four corners of the three semi-field cages in a randomized complete block design. To avoid contamination, specific semi-field cages were dedicated to the test and controls.

\section{Liquid-chromatography-mass spectrometry (LC-MS) quantification of the amount of PPF carried by an individual mosquito and transferred to a water sample} An enamel bowl (diameter $0.42 \mathrm{~m}$ ) filled with $7 \mathrm{~L}$ of nonchlorinated tap water was introduced into a $60 \times 60 \times 60 \mathrm{~cm}$ cage (BugDorm-2120F; MegaView Science Taiwan). The top of the bowl was covered with black fibre-glass netting gauze treated with $3.5 \mathrm{~g}$ PPF dust (average $20.3 \mathrm{~g} \mathrm{PPF} / \mathrm{m}^{2}$ retained on gauze on weighing) as described above. Gravid An. gambiae s.s. were introduced into the cage and monitored for contact with the PPF-treated netting gauze. At any time, there were only two females in the cage. Females that contacted the PPF-treated netting material at least twice were gently aspirated from the cage into holding containers.
Two different tests were conducted with females that contacted the PPF-treated netting. First, 200 potentially contaminated females were individually transferred into $1.5 \mathrm{ml}$ Eppendorf tubes and frozen at $-70{ }^{\circ} \mathrm{C}$ until they were used to quantify the amount of PPF on their body. Secondly, 30 potentially contaminated females were used to determine the amount of PPF that a single mosquito transfers to water during oviposition. For this, bioassays were conducted by introducing these females individually into $15 \mathrm{~cm} \times 15 \mathrm{~cm} \times 15 \mathrm{~cm}$ cages provided with a glass cup (Pyrex ${ }^{\circ}, 100 \mathrm{ml}$, diameter $7 \mathrm{~cm}$ ) filled with $100 \mathrm{ml}$ of non-chlorinated tap water. The females were left overnight in the cages to lay eggs. The following morning the glass cups were assessed for presence of eggs laid.

To confirm the transfer of PPF into the oviposition water, 10 insectary-reared late instar An. gambiae s.s. larvae were introduced into all cups in which females had laid eggs and monitored for adult emergence as described above. When all introduced larvae had died or emerged as adults, the water from the cups was transferred into $50 \mathrm{ml}$ glass jars. The water samples were frozen at $-70^{\circ} \mathrm{C}$ awaiting chromatographic quantification of PPF in the samples. Comparisons were made to a control group of gravid females that were unexposed to PPF. Thirty replicates of test and control cages were done.

For quantification of the amount of PPF that contaminates a gravid mosquito when she makes contact with a PPF-treated netting material, PPF was washed off the body of individual mosquitoes using $1.5 \mathrm{ml}$ methanol (Sigma Aldrich, 99.9\% HPLC grade) in Eppendorf tubes. The content of the Eppendorf tubes was agitated in a sonicator (Branson 2510 Ultrasonic cleaner, Eagle Road, Danbury) at $25^{\circ} \mathrm{C}$ for $5 \mathrm{~min}$. It was then centrifuged at $13,000 \mathrm{rpm}$ $(\mathrm{rpm})$ for $5 \mathrm{~min}$ in a microcentrifuge $\left(\mathrm{PRISM}^{\mathrm{rm}}\right)$. The supernatant was transferred into $2 \mathrm{ml}$ glass vials and used for detection of PPF by liquid chromatography-mass spectrometry (LC-MS).

To detect PPF in water samples used in bioassays, the samples were first pooled into groups of 10 before extraction $(10 \times 50 \mathrm{ml})$. Thus, there were six pools of water samples in which females that contacted PPF laid eggs and another six pools of water samples in which females unexposed to PPF laid eggs. Each pool of water sample $(500 \mathrm{ml})$ was extracted in $200 \mathrm{ml}$ chloroform (Sigma Aldrich, 99.9\% HPLC grade) to separate the aqueous and organic layers. The organic layer, where PPF was expected to dissolve, was concentrated by evaporating it to dryness in a rotary evaporator (Heidolph Instruments, Germany). The residue was dissolved in $1 \mathrm{ml}$ methanol and stored at $4{ }^{\circ} \mathrm{C}$ awaiting analysis. To assist in quantification of PPF, a known concentration $(0.00002 \mu \mathrm{g})$ of 4-benzylbiphenyl (99\%, Sigma Aldrich) was added into each extracted water sample as internal standard just before the LC-MS run. The LC-MS run was performed using electron 
spray ionization (LC/ESI-MS). First, the standards of pure $10 \%$ PPF and 4-benzylbiphenyl were initially run separately in the LC-MS system to confirm the retention times of PPF and the internal standard. PPF used as standard was prepared by dissolving $40 \mathrm{mg}$ of PPF (10\%) in 1.5 $\mathrm{ml}$ ethanol in a $2 \mathrm{ml}$ glass vial. This was agitated in a sonicator at $25^{\circ} \mathrm{C}$ for $5 \mathrm{~min}$. The mixture was centrifuged at 13 , $000 \mathrm{rpm}$ for $5 \mathrm{~min}$. The supernatant was transferred into 2 $\mathrm{ml}$ glass vials ready for detection of PPF. The peaks of PPF and 4-benzylbiphenyl at the retention times were identified based on the molecular masses of their individual ions (molecular masses of PPF-322 and 4-benzylbiphenyl-247).

The LC/ESI-MS used consisted of a quaternary LC pump (Model 1200) coupled to Agilent MSD 6120-Single quadruple MS with electrospray source (Palo Alto, CA). The MS component of the system was used to verify the peak assigned to PPF or 4-benzylbiphenyl as the active ingredients based on the identification of molecular masses of the ions. The system was controlled using ChemStation software (Hewlett-Packard). Reverse-phase liquid chromatography was performed using an Agilent Technologies 1200 infinite series LC, equipped with a Zorbax Eclipse Plus $\mathrm{C}_{18}$ column, $4.6 \times 100 \mathrm{~mm} \times 3.5 \mu \mathrm{m}$ (Phenomenex, Torrance, CA). A gradient using A ( $5 \%$ formic acid in LCgrade ultra pure $\mathrm{H}_{2} \mathrm{O}$ ) and $\mathrm{B}$ (LC-grade methanol) (Sigma, St. Louis, MO) was used; 0-5 min, $95-100 \%$ B; $5-10$ min, $100 \% \mathrm{~B} ; 100-5 \mathrm{~min}$. The mobile phase liquid was acetonitrile (Sigma Aldrich). The flow rate was held constant at $0.7 \mathrm{~mL} \mathrm{~min}^{-1}$. The sample injection volume was $100 \mu \mathrm{l}$, and data were acquired in a full-scan positive-ion mode using a 100 to $500 \mathrm{~m} / z$ scan range. The dwell time for each ion was $50 \mathrm{~ms}$. Other parameters of the mass spectrometer were as follows: capillary voltage, $3.0 \mathrm{kV}$; cone voltage, $70 \mathrm{~V}$; extract voltage, $5 \mathrm{~V}$; RF voltage, $0.5 \mathrm{~V}$; source temperature, $110^{\circ} \mathrm{C}$; nitrogen gas temperature for desolvation, $350^{\circ} \mathrm{C}$; and nitrogen gas flow for desolvation, $400 \mathrm{~L} / \mathrm{h}$.

\section{Data analysis}

Data were analysed in $\mathrm{R}$ statistical software package version 2.13. Generalized estimating equations (GEE) were used to analyse all data with experimental round/night included as repeated measure in the models [43, 44]. Data collected in cage and semi-field experiments to determine the transfer of PPF to water were analysed as proportions. Proportions were analysed by fitting a binomial distribution with a logit function and an exchangeable correlation matrix. Preliminary cage bioassays testing the two PPF formulations were analysed by including treatment (cage with untreated bait-station, bait-station treated with PPF dust or PPF dust formulated in oil) as fixed factor with the control cage (cage with untreated bait-station) used as the reference [45]. For the analysis of the semi-field experiments, the open pond ID identified by its distance from the bait-station was used as the fixed factor with the pond closest to the bait-station used as the reference. Count data evaluating the number of mosquitoes visiting ponds treated with soil infusion or cedrol were fitted to a Poisson distribution with a log link function. Here the ponds were included in the model as fixed factors with the bait-station used as reference. All means (proportions or counts) per treatment and their corresponding 95\% confidence intervals (CIs) were modelled as the exponential of the parameter estimated for the individual models with no intercept included.

\section{Results}

Gravid Anopheles gambiae s.s. pick up more PPF when the PPF is applied on the netting surface as dust than when applied as PPF formulated in oil

Both methods of applying PPF on the netting gauze of the bait-station led to the transfer of PPF by females to the open oviposition cups. This is confirmed by the significant reduction in the emergence of adults from larvae introduced into oviposition cups in treatment cages with bait-station treated with PPF compared to the control cages (Fig. 3 and Table 1). However, the adult mosquito emergence rates were five times lower when the PPF was applied on the netting as dust than when it was formulated in oil.

\section{Oviposition attractants can lure gravid An. gambiae s.s. to a bait-station under semi-field conditions}

The number of mosquitoes trapped on the sticky screens placed over ponds containing soil infusion or cedrol at 5 ppm or 20 ppm was significantly higher than the number trapped over ponds with untreated water (Table 2). The attractiveness of soil infusion and water treated with 5 ppm cedrol was similar and not very strong; a female was only approximately 1.3 times more likely to land on the test pond than on a control pond (Table 2). However, when the water was treated with $20 \mathrm{ppm}$ of cedrol, it was approximately twice as likely for a female to be trapped on the single test pond compared to any of the three control ponds in the experiment (Table 2).

\section{Transfer of PPF by gravid An. gambiae s.s. is dependent on the distance of the oviposition habitat from the bait-station}

In all semi-field cages where gravid females were released inside the hut, eggs were observed in all open ponds on any experimental night. In the absence of PPFtreated netting gauze on the bait-station as well as in the absence of gravid females in a semi-field cage, on average $86 \%$ (95\% CI $81-89 \%$ ) of larvae introduced into ponds emerged as adults. For some unexplained reason there were differences in the emergence rates of larvae introduced into the ponds in the two control set-ups. 


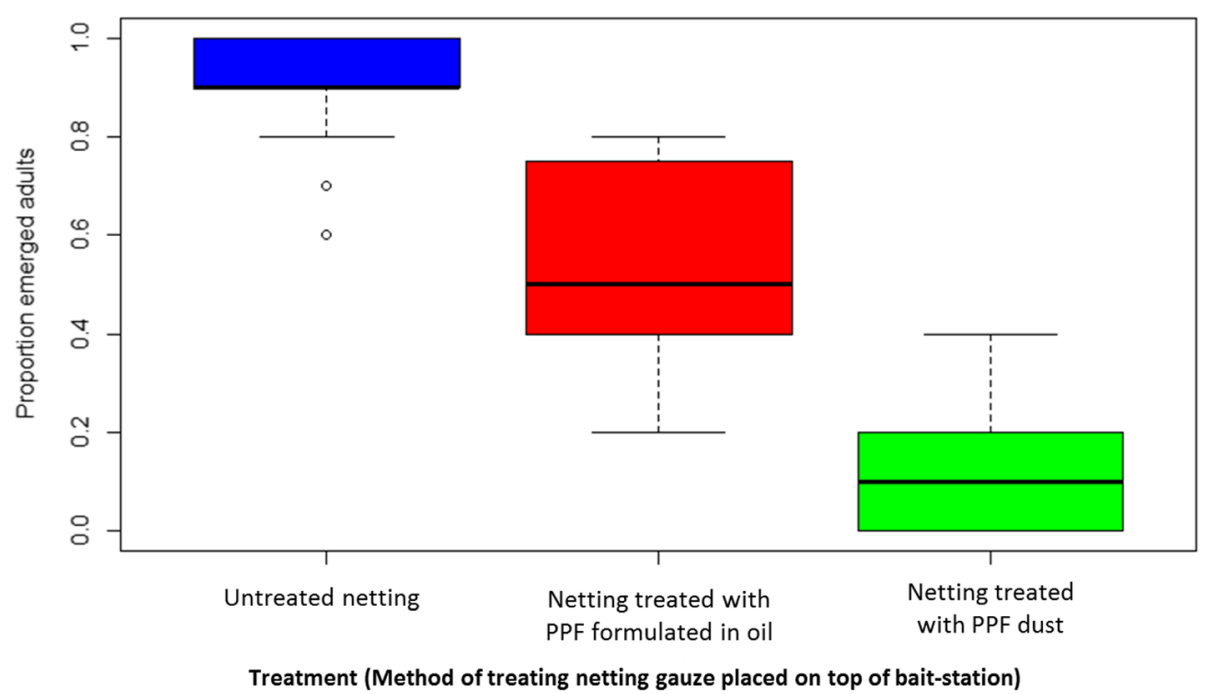

Fig. 3 Box and whisker plots showing the median proportion and interquartile range of adult emerged in cage experiments to determine the best method to treat netting with PPF

The emergence of larvae in the control experiment where no mosquitoes were released but PPF-treated netting placed over the bait-station was consistently higher than in the other control experiment where mosquitoes were released but untreated netting placed over the bait-station (Table 3). This might have been due to some microclimate differences in the two semi-field cages or an unexplained interaction between the early instars originating from eggs laid by gravid females and insectary-reared larvae introduced into ponds in one of the control semi-field cage. Importantly, in both control experiments, emergence rates were similar in all three open ponds (Table 3) and it can be excluded that wind transferred PPF from the bait-station to the open ponds.

The presence of a PPF-treated bait-station in the test cage reduced the emergence of adults from the three open ponds confirming that PPF was transferred by the released gravid females. On average in the test cage, 25\% (95\% CI 22-29\%) of introduced larvae emerged from the pond closest to PPF-treated dissemination station. When comparing the emergence rates between test and control experiments, significant emergence inhibition was observed for the two ponds closest to the bait-station. It was approximately 24 times less likely for an adult to emerge from the ponds closest to a bait-station (located
$4.4 \mathrm{~m}$ away) and 6 times less likely from the ponds that were approximately twice as far away from the bait-station (located $8.4 \mathrm{~m}$ away) than it was for an adult to emerge from any pond in the control experiments (Table 3). No emergence inhibition was recorded from the pond that was furthest away from the bait-station, located in the opposite corner and obstructed by the hut suggesting that no or an insufficient amount of PPF was transferred to this pond.

\section{Gravid An. gambiae s.s. transfer only a small fraction of the PPF they pick up to the oviposition substrate}

Ninety percent $(n=30)$ of females that landed on PPFtreated netting laid eggs when provided with water in a glass cup in a cage. A similar number $(n=30)$ of unexposed (control) females laid eggs. Adult emergence rates from larvae that were introduced into the cups differed significantly (Table 4). It was 17 times less likely for a larva to emerge when it was introduced into water in which PPF exposed female had laid eggs than when introduced into a cup in which unexposed female had laid eggs (Table 4), confirming that PPF was transferred.

Based on the control emergence, the corrected percent emergence inhibition observed was 52\% (95\% CI 46-56\%).

Table 1 Adult emergence rates from larvae introduced into oviposition cups in cage experiments comparing PPF dust and PPF-oil applications for the bait-station

\begin{tabular}{llll}
\hline Method of PPF presentation & Mean proportion emergence $(95 \% \mathrm{Cl})$ & $\begin{array}{l}\text { Odds ratio } \\
(95 \% \mathrm{Cl})\end{array}$ & 1 \\
\hline No PPF & $0.89(0.83-0.93)$ & $0.14(0.07-0.28)$ & $<0.001$ \\
Oil-formulated PPF & $0.55(0.35-0.62)$ & $0.02(0.006-0.036)$ & $<0.001$ \\
PPF dust & $0.11(0.07-0.17)$ & $<$
\end{tabular}


Table 2 Semi-field oviposition choice tests evaluating the attractiveness of oviposition substrates added to water in comparison to ponds filled with water only

\begin{tabular}{|c|c|c|c|}
\hline Treatment & Mean number of females attracted to pond $(95 \% \mathrm{Cl})$ & Rate ratio $(95 \% \mathrm{Cl})$ & $p$-value \\
\hline \multicolumn{4}{|c|}{ Testing the attraction to soil infusion } \\
\hline soil infusion & $39(33-45)$ & 1 & \\
\hline water (pond 1) & $29(25-33)$ & $0.74(0.59-0.93)$ & 0.011 \\
\hline water (pond 2) & $26(22-31)$ & $0.67(0.54-0.82)$ & $<0.001$ \\
\hline water (pond 3) & $27(23-31)$ & $0.70(0.56-0.88)$ & 0.002 \\
\hline \multicolumn{4}{|c|}{ Testing the attraction to water treated with $5 \mathrm{ppm}$ cedrol } \\
\hline 5 ppm cedrol & $33(30-35)$ & 1 & \\
\hline water (pond 1) & $25(21-29)$ & $0.76(0.63-0.92)$ & 0.005 \\
\hline water (pond 2) & $26(23-29)$ & $0.80(0.70-0.91)$ & 0.001 \\
\hline water (pond 3) & $26(23-30)$ & $0.81(0.70-0.94)$ & 0.005 \\
\hline \multicolumn{4}{|c|}{ Testing the attraction to water treated with 20 ppm cedrol } \\
\hline 20 ppm cedrol & $52(46-60)$ & 1 & \\
\hline water (pond 1) & $28(24-33)$ & $0.54(0.43-0.67)$ & $<0.001$ \\
\hline water (pond 2) & $32(28-38)$ & $0.62(0.48-0.80)$ & $<0.001$ \\
\hline water (pond 3) & $27(21-35)$ & $0.52(0.38-0.72)$ & $<0.001$ \\
\hline
\end{tabular}

In other words, an individual female transferred the concentration of PPF to $100 \mathrm{ml}$ of water that inhibited emergence of approximately $50 \%$ of larvae $\left(\mathrm{EI}_{50}\right)$.

Chemical analysis showed that it was impossible to detect the PPF that was washed off the body of a single mosquito. Therefore, samples from 20 individuals were pooled for analysis on the LC-MS system. In total, PPF was washed off 140 individuals that had made contact with PPF (tests) and a similar number that was unexposed (controls). Consequently, there were seven pools

Table 3 Adult emergence rates of larvae introduced into open ponds in the three experiments to evaluate transfer of PPF in semifield cages

\begin{tabular}{|c|c|c|c|}
\hline Ponds (distance betweeen pond and pond that served as bait station) & $\begin{array}{l}\text { Mean proportion adult } \\
\text { emergence } \\
(95 \% \mathrm{Cl})\end{array}$ & $\begin{array}{l}\text { Odds ratio } \\
(95 \% \mathrm{Cl})\end{array}$ & $p$-value \\
\hline \multicolumn{4}{|l|}{ Control 1 - Mosquitoes released in semi-field cage \& bait-station without PPF } \\
\hline closest to bait station (4.4 m) & $0.85(0.82-0.87)$ & 1 & \\
\hline medium to bait-station ( $8.4 \mathrm{~m}$ ) & $0.83(0.80-0.86)$ & $0.87(0.62-1.23)$ & 0.443 \\
\hline furthest to bait-station (10.3 m) & $0.84(0.81-0.87)$ & $0.99(0.71-1.37)$ & 0.944 \\
\hline \multicolumn{4}{|l|}{ Control 2 - No mosquitoes released in semi-field cage \& bait-station with PPF } \\
\hline closest to bait-station (4.4 m) & $0.89(0.86-0.91)$ & 1 & \\
\hline medium to bait-station ( $8.4 \mathrm{~m}$ ) & $0.89(0.87-0.92)$ & $1.03(0.72-1.49)$ & 0.854 \\
\hline furthest to bait-station (10.3 m) & $0.88(0.85-0.91)$ & $0.94(0.65-1.34)$ & 0.721 \\
\hline \multicolumn{4}{|l|}{ Test - Mosquitoes released in semi-field cage \& bait-station with PPF } \\
\hline closest to bait-station (4.4 m) & $0.25(0.22-0.29)$ & 1 & \\
\hline medium to bait-station ( 8.4 m) & $0.58(0.54-0.62)$ & $4.07(3.19-5.21)$ & $<0.001$ \\
\hline furthest to bait-station (10.3 m) & $0.92(0.89-0.94)$ & $33.89(24.16-48.47)$ & $<0.001$ \\
\hline \multicolumn{4}{|c|}{ Emergence inhibition due to auto-dissemination - comparison of test with control } \\
\hline control & $0.89(0.84-0.94)$ & 1 & \\
\hline closest test pond (4.4 m) & $0.25(0.20-0.33)$ & $0.042(0.023-0.077)$ & $<0.001$ \\
\hline medium test $(8.4 \mathrm{~m})$ & $0.58(0.51-0.66)$ & $0.173(0.098-0.303)$ & $<0.001$ \\
\hline furthest test $(10.3 \mathrm{~m})$ & $0.92(0.85-0.98)$ & $1.437(0.846-2.444)$ & 0.180 \\
\hline
\end{tabular}


Table 4 Adult emergence rate of late instar larvae introduced into oviposition cups in which Anopheles females laid eggs

\begin{tabular}{llll}
\hline & $\begin{array}{l}\text { Mean proportion } \\
\text { emergence }(95 \% \mathrm{Cl})\end{array}$ & $\begin{array}{l}\text { Odds ratio } \\
(95 \% \mathrm{Cl})\end{array}$ & -value \\
\hline $\begin{array}{l}\text { Control - unexposed } \\
\text { females }\end{array}$ & $0.93(0.89-0.97)$ & 1 & \\
$\begin{array}{l}\text { Test - PPF-exposed } \\
\text { females }\end{array}$ & $0.45(0.39-0.51)$ & $0.06(0.03-0.10)$ & 0.007 \\
\hline
\end{tabular}

of females in tests and in controls. No PPF was detected in any of the washes from control mosquitoes. PPF was below the detection limit in two of the test pools. The estimated amount of PPF washed off an individual female from the remaining five test pools was $141 \mu \mathrm{g}, 120 \mu \mathrm{g}$, $93 \mu \mathrm{g}, 117 \mu \mathrm{g}$ and $89 \mu \mathrm{g}$. This results in an average of $112 \mu \mathrm{g}$ (95\% CI 103-123 $\mu \mathrm{g})$ PPF washed off an individual mosquito. However, this is likely to be an overestimate since PPF levels were below detection limits in two sample pools which were not included in calculating this average. Assuming that an individual female transfers this entire amount of PPF to oviposition cups with $100 \mathrm{ml}$ of water, we would expect a concentration of $1.12 \mathrm{mg}$ PPF/L (1.12 ppm).

PPF was detected in three of the six test water samples but never in the control water samples. The estimated concentration of PPF in the individual water samples in the three positive pools were $330 \mathrm{ng} / \mathrm{L}, 160 \mathrm{ng} / \mathrm{L}$ and $190 \mathrm{ng} / \mathrm{L}$. Therefore, the average estimated concentration of PPF in a single oviposition cup was approximately $230 \mathrm{ng} / \mathrm{L}$ (95\% CI $180-290 \mathrm{ng} / \mathrm{L})$; which is equivalent to $0.00023 \mathrm{mg} / \mathrm{L}$ $(0.00023 \mathrm{ppm})$. Similarly, this is likely to be an overestimate since in three of the test water samples PPF was below the detection limit. Based on the bioassay results, this is the concentration that provided around $50 \%$ emergence inhibition of introduced larvae.

\section{Discussion}

To our knowledge this is the first study to have developed a prototype bait-station for gravid An. gambiae s.s. for the auto-dissemination of PPF to aquatic habitats. We show in principle that gravid females can be attracted to a target, successfully pick up PPF and consequently transfer it to an aquatic habitat while laying eggs, thereby killing immature mosquito stages. Even though 200 gravid females were released in a relatively small space of approximately $170 \mathrm{~m}^{3}$, adult emergence from larval habitats was only inhibited by around $70 \%$ from ponds located less than $5 \mathrm{~m}$ from the bait-station but not from ponds $10 \mathrm{~m}$ away. These results strongly suggest that even if females can be lured successfully to a bait-station, they are most likely to transfer the PPF only to the closest available and detectable oviposition habitats.

This study highlights a number of challenges that need to be taken into consideration for the development of an efficient auto-dissemination approach for African malaria vectors. Based on previous work we consider exposing gravid females to PPF to be the most effective way to ensure transfer of the insecticide to an aquatic habitat [35]. This is because exposure of the female mosquito to PPF earlier in her life has significant impact on her fertility and fecundity $[33,34,36,46]$, lowering the females predisposition to visit an aquatic habitat. Attracting the gravid female is however more challenging than attracting a hostseeking or resting female, due to the scarcity of synthetic oviposition attractants $[38,47,48]$.

Our study confirms previous findings that the chemical compound, cedrol [40], attracts gravid $A n$. gambiae S.s. and might be used in a novel attract (-release) -andkill approach. However, contrary to earlier findings by Lindh et al. [40] where twice as many gravid An. gambiae s.l. were recovered with $5 \mathrm{ppm}$ cedrol than with water alone, we only achieved the same attractiveness with $20 \mathrm{ppm}$ cedrol. This difference is likely due to the absence of directional air movement generated by the bait-station in our study. Lindh et al. [40] used modified BG-Sentinel traps that produce an air circulation with the help of a fan which likely led to the release of a larger amount of cedrol and water vapour, providing a stronger signal for oviposition site-seeking females. The absence of emergence inhibition from the ponds furthest away from the bait-station might not only indicate that gravid females flew the shortest distance from the baitstation to oviposit, but is likely also an indicator of the moderate attractiveness of the bait-station. Gravid females were released inside an experimental hut and assuming a random dispersal out through the open eaves, it is reasonable to assume, that a proportion of gravid females leaving the hut through the eave facing away from the bait-station went straight to the next open pond to lay eggs. To efficiently use a limited number of bait-stations in the natural field environment that is characterized with numerous aquatic habitats [18, 22], the attractiveness of bait-stations might be improved through innovative release technologies and formulation of more attractive chemical blends [47, 49-51].

Gravid females transferred more PPF from treated surfaces when PPF was applied as dust than when formulated in oil. There are two possible explanations for this. First, the oil might reduce the transfer of PPF to mosquitoes, with more of it adhering to the netting surface. Second, it might also be that the oil contributed to a larger proportion of PPF remaining on the mosquito's body, thus limiting the chance of PPF getting in contact with water. Presumably, the hydrophobic oil attaches more strongly to the hydrophobic cuticle than to water [52]. In the approach used in this study, a lot of the active ingredient remained on the netting gauze and was wasted since not all the material was taken up. 
Furthermore, our chromatographic analyses reveal that an individual female transferred $>4800$ times less PPF to the oviposition cup during egg-laying than the amount picked up from the treated netting. PPF on the insect cuticle is likely to decrease with time due to loss during flight, resting and penetration through the insect cuticle [53-55]. The chromatography analyses here confirm our findings from the bioassay, that a single female could transfer sufficient PPF to inhibit the emergence of 50\% (EI50) of the larvae in $100 \mathrm{ml}$ volumes of water. The average concentration of PPF detected in water used in the bioassays was $0.00023 \mathrm{mg} / \mathrm{L}$ (95\% CI 0.000180 $0.000290 \mathrm{mg} / \mathrm{L}$ ), which correlates well with previously published results from laboratory assays when the $\mathrm{EI}_{50}$ was established at $0.000120 \mathrm{ng} / \mathrm{L}$ (95\% CI 0.000090 $0.000160 / \mathrm{L}$ ) [56]. The findings are also consistent with previous cage bioassays where females were contaminated in a plastic jar coated with PPF, and a single female caused approximately $50 \%$ of the introduced larvae not to develop into adult [35]. Taken together it appears that this is the average amount of our test formulation that a gravid An. gambiae s.s. can transfer to an aquatic habitat in a test system like ours. In our system, approximately 500 gravid females would be required to visit a water body $1 \mathrm{~m}^{2}$ in area and $10 \mathrm{~cm}$ deep, to transfer the optimal lethal concentration determined in the laboratory, which is highly unlikely under most natural conditions as gravid females comprise a very small proportion of the overall mosquito population. For large-scale application and cost-effective use of the relatively expensive active ingredient there is need to investigate strategies that use PPF more efficiently. Improved technologies such as electrostatic charging of PPF to enhance adherence of insecticide particles on insect body contact with contaminated surface and ensuring delivery of larger amounts of insecticide will be beneficial [49]. Whether this would improve the amount transferred to water or only increase the overall amount carried by the individual mosquito would need to be tested.

Mathematical models show that the success of autodissemination for malaria vector control is dependent on the abundance of adult vectors, the number and stability of larval habitats and persistence of the insecticide used $[28,29]$. The auto-dissemination approach can be more appealing for controlling immature malaria vectors in aquatic habitats that are not easily accessible for insecticide application by teams on the ground [10]. This study highlights that the transfer of PPF to a larval habitat is dependent on the distance of the pond from the bait-station. Ponds closest to the bait-station are most likely to be visited consequently receiving sufficient amounts of PPF to have an impact on immature mosquito development. It is likely that vegetation cover, which was on purpose excluded from the experimental design might have further impacted on the ability of finding a suitable habitat and on the amount of PPF lost due to resting $[55,57]$. Numerous bait-stations would therefore be required in the field for gravid mosquitoes to transfer sufficient lethal doses of PPF to their larval habitats. This is a substantial challenge considering the large number and extensive nature of water bodies utilized by African malaria vectors $[18,22]$.

Comparable semi-field studies to evaluate the possibility of auto-dissemination with PPF were done targeting host-seeking and resting An. arabiensis for PPF exposure using treated clay pots [30-32]. The efficiency of transfer reported from these studies were significantly higher, with an emergence inhibition of over $80 \%$ from the provided aquatic habitats. Factors that might explain the greater impacts in these studies include the use of numerous resting posts as dissemination stations for PPF and fewer, smaller-sized aquatic habitats. For instance, in two of these studies, the authors placed eight resting pots treated with PPF and provided only 2-4 small aquatic habitats of a $2.5 \mathrm{~L}$ capacity [30,31]. Thus, the ratio of dissemination stations to oviposition habitats was 4:1 or 2:1 in these previous studies. This is in comparison to a dissemination station to oviposition habitats ratio of 1:3 in our study. Furthermore, in the previous studies with $A n$. arabiensis, a very large number of 1500-5000 females were either introduced into the system, or reared inside the system [30-32], maximising the likelihood of a mosquito visiting a PPF-treated resting pot and the number of oviposition events in a single aquatic habitat.

A limitation of our study was the assessment of transfer of PPF by females by introducing insectary-reared late instar larvae into test ponds rather than monitoring adult emergence inhibition from larvae that hatch from the eggs laid by PPF-exposed females. This is likely to underestimate the impact of PPF disseminated by females into water bodies since it is expected that the impact on reducing adult emergence will be greater on immature stages that have prolonged exposure to the insecticide during larval development [58].

\section{Conclusion}

Our study carried out under controlled conditions highlights potential limitations of the auto-dissemination strategy for the control of Afrotropical malaria vectors. Our results emphasize the need to investigate the required ratio of bait-stations to aquatic habitats for adult gravid females to transfer sufficient amounts of PPF for efficient control of immature malaria vectors in all aquatic habitats. The skip-oviposition behaviour recently observed in An. gambiae s.s. in cages [45] and in $A n$. arabiensis in the field [59] is likely to benefit the autodissemination approach for malaria vector control since 
gravid females visit several habitats to lay eggs. Nevertheless, significantly more work is required in designing highly attractive bait-stations for gravid malaria vectors by identifying more attractants to compose highly attractive chemical blends, determining better mechanisms for optimum release of the attractants, identifying better and more cost-effective mechanisms for retaining and dispensing of PPF as well as improving the physical components of the bait-station to provide protective barriers from rain.

Additionally, insecticides of greater persistence in the environment than PPF, such as novaluron [26] might benefit the auto-dissemination approach for mosquito control. Most importantly, field evaluations are necessary to confirm the performance of such novel tools under natural conditions during both the dry and rainy seasons. Mosquitoes of other genera such as Culex might be used to amplify the transfer of PPF to larval habitats of An. gambiae s.s. [35], since these mosquitoes frequently share breeding habitats [21-23]. However, it might be challenging to attract this cohabiting species to the same bait-stations. In conclusion, the auto-dissemination strategy using PPF transferred by gravid malaria vectors requires significantly more research before it might be used operationally as a supplementary measure for malaria vector control.

\begin{abstract}
Abbreviations
HPLC: High performance liquid chromatography; icipe-TOC: International Centre of Insect Physiology and Ecology - Thomas Odhiambo Campus; LC/ ESI-MS: Liquid chromatography/Electron spray ionization-Mass spectrometry; LC-MS: Liquid chromatography- Mass spectrometry

Acknowledgements

We would like to thank David Alila and Elisha Obudho from the insectary at icipe-TOC, Mbita for providing mosquitoes for experiments. We thank Baldwyn Torto for providing access to the Chemical Ecology laboratory at icipe-Nairobi and support during the LC-MS analysis. We thank Xavier Cheseto for the technical assistance in conducting the LC-MS. We are also grateful for the technical assistance from Paul Ouma, Gregory Masinde and Rose Atieno. We thank John Lucas for the provision of the insecticide and technical advice.
\end{abstract}

\section{Authors' contributions}

UF conceived the idea for this research. OM, SWL and UF developed the experimental design and protocols. OM implemented the experiments, analysed the data and drafted the manuscript. All authors contributed to the final draft, read and approved the manuscript.

\section{Funding}

Financial support for this research was provided by the following organizations and agencies: National Institute of Health (NIH) grant no. R01AI082537; UK's Department for International Development (DFID); Swedish International Development Cooperation Agency (sida); the Swiss Agency for Development and Cooperation (SDC); Federal Democratic Republic of Ethiopia; and the Kenyan Government.

\section{Availability of data and materials}

All data will be made available on reasonable request to the senior author.

\section{Ethics approval and consent to participate}

Ethical approval for this study was obtained from the Kenya Medical Research Institute's Ethical Review Committee (Protocol no. 422).

\section{Consent for publication}

Not applicable.

\section{Competing interests}

Sumitomo Chemicals, Japan, provided the experimental formulation of the insecticide for this study free of charge. Nevertheless, neither the manufacturer nor any of the funders of this work had any role in the design, analysis or interpretation of the results, nor in the drafting of the manuscript.

\section{Author details}

${ }^{1}$ International Centre of Insect Physiology and Ecology, Human Health Theme, Nairobi, Kenya. 'London School of Hygiene and Tropical Medicine, London, UK. ${ }^{3}$ Durham University, Durham, UK.

Received: 23 June 2019 Accepted: 4 September 2019

Published online: 11 September 2019

\section{References}

1. WHO. World Malaria Report 2018. Geneva: World Health Organization. https://www.who.int/malaria/publications/world-malaria-report-2018/en/

2. Steketee RW, Campbell CC. Impact of national malaria control scale-up programmes in Africa: magnitude and attribution of effects. Malar J. 2010:9:299.

3. Tambo E, Adedeji AA, Huang F, Chen JH, Sen ZS, Tang LH. Scaling up impact of malaria control programmes: a tale of events in sub-Saharan Africa and People's republic of China. Infect Dis Poverty. 2012;1(1):7.

4. WHO. World Malaria Report 2017. Geneva: World Health Organization. https://www.who.int/malaria/publications/world-malaria-report-2017/en/

5. Hemingway J, Shretta R, Wells TNC, Bell D, Djimdé AA, Achee N, et al. Tools and strategies for malaria control and elimination: what do we need to achieve a grand convergence in malaria? PLoS Biol. 2016;14(3):e1002380.

6. Killeen GF, Tatarsky A, Diabate A, Chaccour CJ, Marshall JM, Okumu FO, et al Developing an expanded vector control toolbox for malaria elimination. BMJ Glob Heal. 2017;2(2):e000211.

7. WHO. Global technical strategy for malaria 2016-2030. Geneva: World Health Organization. https://www.who.int/malaria/publications/atoz/ 9789241564991/en/

8. Stuckey EM, Stevenson J, Galactionova K, Baidjoe AY, Bousema T, Odongo $W$, et al. Modeling the cost effectiveness of malaria control interventions in the highlands of western Kenya. PLoS One. 2014;9(10):e107700.

9. Tusting LS, Thwing J, Sinclair D, Fillinger U, Gimnig J, Ke B, et al. Mosquito larval source management for controlling malaria ( review ). Cochrane Database Syst Rev. 2016;(8):CD008923.

10. Fillinger $U$, Lindsay SW. Larval source management for malaria control in Africa: myths and reality. Malar J. 2011:10:353.

11. Fillinger $U$, Ndenga B, Githeko A, Lindsay SW. Integrated malaria vector control with microbial larvicides and insecticide-treated nets in western Kenya: a controlled trial. Bull World Health Organ. 2009;87(9):655-65.

12. Geissbühler Y, Kannady K, Chaki PP, Emidi B, Govella NJ, Mayagaya V, et al. Microbial larvicide application by a large-scale, community-based program reduces malaria infection prevalence in urban Dar Es Salaam, Tanzania. PLoS One. 2009;4(3):e5107.

13. Maheu-Giroux M, Castro MC. Impact of community-based larviciding on the prevalence of malaria infection in Dar Es Salaam, Tanzania. PLoS One. 2013: 8(8):e71638

14. Killeen GF, Govella NJ, Mlacha YP, Chaki PP. Suppression of malaria vector densities and human infection prevalence associated with scale-up of mosquito-proofed housing in Dar Es Salaam, Tanzania: re-analysis of an observational series of parasitological and entomological surveys. Lancet Planet Heal. 2019:3(3):e132-43.

15. Fillinger U, Kannady K, William G, Vanek MJ, Dongus S, Nyika D, et al. A tool box for operational mosquito larval control: preliminary results and early lessons from the urban malaria control Programme in Dar Es Salaam, Tanzania. Malar J. 2008;7:20.

16. Majambere S, Pinder M, Fillinger U, Ameh D, Conway DJ, Green C, et al. Is mosquito larval source management appropriate for reducing malaria in areas of extensive flooding in the Gambia? A cross-over intervention trial. Am J Trop Med Hyg. 2010;82(2):176-84.

17. Chaki PP, Govella NJ, Shoo B, Hemed A, Tanner M, Fillinger U, et al. Achieving high coverage of larval-stage mosquito surveillance: challenges for a community-based mosquito control programme in urban Dar Es Salaam, Tanzania. Malar J. 2009;8(1):311. 
18. Majambere S, Fillinger U, Lindsay SW, Green C, Sayer DR. Spatial distribution of mosquito larvae and the potential for targeted larval control in the Gambia. Am J Trop Med Hyg. 2008;79(1):19-27.

19. Gu W, Novak R. Habitat-based modeling of mosquito larval interventions on entomological inoculation rates, incidence and prevalence of malaria. Am J Trop Med Hyg. 2005;73(3):546-52

20. Gu W, Utzinger J, Novak RJ. Habitat-based larval interventions: a new perspective for malaria control. Am J Trop Med Hyg. 2008;78(1):2-6.

21. Ndenga BA, Simbauni JA, Mbugi JP, Githeko AK, Fillinger U. Productivity of malaria vectors from different habitat types in the western Kenya highlands. PLoS One. 2011;6(4):e19473.

22. Fillinger U, Sonye G, Killeen GF, Knols BGJ, Becker N. The practical importance of permanent and semipermanent habitats for controlling aquatic stages of Anopheles gambiae sensu lato mosquitoes: operational observations from a rural town in western Kenya. Trop Med Int Heal. 2004;9: 1274-89.

23. Fillinger U, Sombroek H, Majambere S, Van Loon E, Takken W, Lindsay SW. Identifying the most productive breeding sites for malaria mosquitoes in the Gambia. Malar J. 2009;8(1):62.

24. Caputo B, lenco A, Cianci D, Pombi M, Petrarca V, Baseggio A, et al. The "auto-dissemination" approach: a novel concept to fight Aedes albopictus in urban areas. PLoS Negl Trop Dis. 2012;6(8):e1793.

25. Unlu I, Suman DS, Wang Y, Klingler K, Faraji A, Gaugler R. Effectiveness of autodissemination stations containing pyriproxyfen in reducing immature Aedes albopictus populations. Parasit Vectors. 2017;10(1):139.

26. Swale DR, Li Z, Kraft JZ, Healy K, Liu M, David CM, et al. Development of an autodissemination strategy for the deployment of novel control agents targeting the common malaria mosquito, Anopheles quadrimaculatus say (Diptera: Culicidae). PLoS Negl Trop Dis. 2018;12(4):e0006259.

27. Mian LS, Dhillon MS, Dodson L. Field evaluation of pyriproxyfen against mosquitoes in catch basins in southern California. J Am Mosq Control Assoc. 2017:33(2):145-7.

28. Devine GJ, Killeen GF. The potential of a new larviciding method for the control of malaria vectors. Malar J. 2010;9(1):142.

29. Kiware SS, Corliss G, Merrill S, Lwetoijera DW, Devine G, Majambere S, et al. Predicting scenarios for successful autodissemination of pyriproxyfen by malaria vectors from their resting sites to aquatic habitats; description and simulation analysis of a field-parameterizable model. PLoS One. 2015;10(7):e0131835.

30. Lwetoijera D, Harris C, Kiware S, Dongus S, Devine GJ, McCall PJ. Effective autodissemination of pyriproxyfen to breeding sites by the exophilic malaria vector Anopheles arabiensis in semi-field settings in Tanzania. Malar J. 2014; 13(1):161.

31. Lwetoijera DW, Harris C, Kiware SS, Killeen GF, Dongus S, Devine GJ, et al. Short report: comprehensive sterilization of malaria vectors using pyriproxyfen: a step closer to malaria elimination. Am J Trop Med Hyg. 2014;90(5):852-5.

32. Lwetoijera D, Kiware S, Okumu F, Devine GJ, Majambere S. Autodissemination of pyriproxyfen suppresses stable populations of Anopheles arabiensis under semi-controlled settings. Malar J. 2019;18(1):166

33. Djènontin A, Ahoua Alou LP, Koffi A, Zogo B, Duarte E, N'Guessan R, et al. Insecticidal and sterilizing effect of Olyset duo ${ }^{\circledR}$, a permethrin and pyriproxyfen mixture net against pyrethroid-susceptible and -resistant strains of Anopheles gambiae s.s. : a release-recapture assay in experimental huts. Parasite. 2015;22:27.

34. Ngufor C, N'Guessan R, Fagbohoun J, Odjo A, Malone D, Akogbeto M, et al. Olyset $\mathrm{duo}^{\oplus}$ (a pyriproxyfen and permethrin mixture net): an experimental hut trial against pyrethroid resistant Anopheles gambiae and Culex quinquefasciatus in southern Benin. PLoS One. 2014;9(4):e93603.

35. Mbare O, Lindsay SW, Fillinger U. Pyriproxyfen for mosquito control: female sterilization or horizontal transfer to oviposition substrates by Anopheles gambiae sensu stricto and Culex quinquefasciatus. Parasit Vectors. 2014;7(1):280.

36. Ohashi K, Nakada K, Ishiwatari T, Miyaguchi J, Shono Y, Lucas JR, et al. Efficacy of pyriproxyfen-treated nets in sterilizing and shortening the longevity of Anopheles gambiae (Diptera: Culicidae). J Med Entomol. 2012; 49(5):1052-8.

37. Harris C, Lwetoijera DW, Dongus S, Matowo NS, Lorenz LM, Devine GJ, et al. Sterilising effects of pyriproxyfen on Anopheles arabiensis and its potential use in malaria control. Parasit Vectors. 2013;6(1):144.

38. Okal MN, Francis B, Herrera-Varela M, Fillinger U, Lindsay SW. Water vapour is a pre-oviposition attractant for the malaria vector Anopheles gambiae sensu stricto. Malar J. 2013;12(1):365.
39. Herrera-Varela M, Lindh J, Lindsay SW, Fillinger U. Habitat discrimination by gravid Anopheles gambiae sensu lato - a push-pull system. Malar J. 2014;13(1):133.

40. Lindh JM, Okal MN, Herrera-Varela M, Borg-Karlson A-K, Torto B, Lindsay SW, et al. Discovery of an oviposition attractant for gravid malaria vectors of the Anopheles gambiae species complex. Malar J. 2015;14(1):119.

41. Charlwood JD, Kessy E, Yohannes K, Protopopoff N, Rowland M, LeClair C. Studies on the resting behaviour and host choice of Anopheles gambiae and An. arabiensis from Muleba, Tanzania. Med Vet Entomol. 2018;32(3):263-70.

42. Das S, Garver L, Dimopoulos G. Protocol for mosquito rearing (A. gambiae). J Vis Exp. 2007;(5):e221.

43. Wang M. Generalized estimating equations in longitudinal data analysis: a review and recent developments. Adv Stat. 2014;2014:303728.

44. Ma Y, Mazumdar M, Memtsoudis SG. Beyond repeated-measures analysis of variance: advanced statistical methods for the analysis of longitudinal data in anesthesia research. Reg Anesth Pain Med. 2012;37(1):99-105.

45. Okal MN, Lindh JM, Torr SJ, Masinde E, Orindi B, Lindsay SW, et al. Analysing the oviposition behaviour of malaria mosquitoes: design considerations for improving two-choice egg count experiments. Malar J. 2015;14(1):250.

46. Koama B, Namountougou M, Sanou R, Ndo S, Ouattara A, Dabiré RK, et al. The sterilizing effect of pyriproxyfen on the malaria vector Anopheles gambiae: physiological impact on ovaries development. Malar J. 2015;14(1):101.

47. Eneh LK, Saijo H, Karin A, Karlson B, Lindh JM, Rajarao GK. Cedrol, a malaria mosquito oviposition attractant is produced by fungi isolated from rhizomes of the grass Cyperus rotundus. Malar J. 2016;15:478.

48. Wondwosen B, Birgersson G, Seyoum E, Tekie H, Torto B, Fillinger U, et al. Rice volatiles lure gravid malaria mosquitoes, Anopheles arabiensis. Sci Rep. 2016:6:37930.

49. Andriessen R, Snetselaar J, Suer RA, Osinga AJ, Deschietere J, Lyimo IN, et al. Electrostatic coating enhances bioavailability of insecticides and breaks pyrethroid resistance in mosquitoes. Proc Natl Acad Sci. 2015;112(39):12081-6.

50. Eneh LK, Fillinger U, Borg Karlson AK, Kuttuva Rajarao G, Lindh J. Anopheles arabiensis oviposition site selection in response to habitat persistence and associated physicochemical parameters, bacteria and volatile profiles. Med Vet Entomol. 2019;33(1):56-67.

51. Wondwosen B, Birgersson G, Tekie H, Torto B, Ignell R, Hill SR. Sweet attraction: sugarcane pollen-associated volatiles attract gravid Anopheles arabiensis. Malar J. 2018;17(1):90.

52. Arkles B. Hydrophobicity, hydrophilicity and Silane surface modification. Gelest Inc. 2015;1:1-84

53. Schneider M, Smagghe G, Pineda S, Viñuela E. The ecological impact of four IGR insecticides in adults of Hyposoter didymator (Hym., Ichneumonidae): pharmacokinetics approach. Ecotoxicology. 2008;17:181.

54. Medina P, Smagghe G, Budia F, del Estal P, Tirry L, Viñuela E. Significance of penetration, excretion, and transovarial uptake to toxicity of three insect growth regulators in predatory lacewing adults. Arch Insect Biochem Physiol. 2002;51:91-101.

55. Itoh $\mathrm{T}$, Kawada $\mathrm{H}$, Abe A, Eshita $\mathrm{Y}$, Rongsriyam $\mathrm{Y}$, Igarashi A. Utilization of bloodfed females of Aedes aegypti as a vehicle for the transfer of the insect growth regulator pyriproxyfen to larval habitats. J Am Mosq Control Assoc. 1994;10:344-7.

56. Mbare O, Lindsay SW, Fillinger U. Dose-response tests and semi-field evaluation of lethal and sub-lethal effects of slow release pyriproxyfen granules (Sumilarv ${ }^{\oplus} 0.5 \mathrm{G}$ ) for the control of the malaria vectors Anopheles gambiae sensu lato. Malar J. 2013:12(1):94.

57. Burkett-Cadena ND, Eubanks MD, Unnasch TR. Preference of female mosquitoes for natural and artificial resting sites. J Am Mosq Control Assoc. 2008;24(2):228-35

58. Invest JF, Lucas JR. Pyriproxyfen as a mosquito larvicide. In: Proceedings of the sixth international conference on urban pests; 2008. p. 239-45. http:// www.icup.org.uk/report/ICUP886.pdf.

59. Odero JO, Fillinger U, Rippon EJ, Masiga DK, Weetman D. Using sibship reconstructions to understand the relationship between larval habitat productivity and oviposition behaviour in Kenyan Anopheles arabiensis. Malar J. 2019;18(1):286.

\section{Publisher's Note}

Springer Nature remains neutral with regard to jurisdictional claims in published maps and institutional affiliations. 